\title{
A educação para o Patrimônio Cultural como estratégia de desenvolvimento local
}

\author{
Education for Cultural Heritage and local development strategy
}

\section{Tassiane Mélo de Freitas}

\author{
Instituto Federal Sul Rio-Grandense - IFRS - Charqueadas - Rio Grande do Sul - Brasil
}

Resumo: O objetivo central deste artigo é apresentar a educação para o Patrimônio Cultural como estratégia essencial no processo de conhecimento, proteção, conservação e promoção dos bens culturais. Salienta-se que, a partir desta proposta, é possível a criação de ideias e ações em favor do desenvolvimento local, de maneira sustentável. No momento em que os sujeitos reconhecem a importância dos componentes patrimoniais existentes em suas comunidades, por meio de ações educativas que estimulem os sentidos e as afetividades, torna-se possível pensar e encaminhar atitudes de reconversão social e econômica e de valorização da memória e identidade, sob o prisma do desenvolvimento sustentável. Inserir o tema do Patrimônio Cultural na pauta sobre a gestão dos espaços públicos das cidades é uma das possíveis maneiras de aliar a questão do Patrimônio Cultural à sustentabilidade. Certamente outras possibilidades, em termos de desenvolvimento local, podem vir a se efetuar tendo em vista a enorme gama de potencialidades apresentadas tanto pelo Patrimônio Material quanto Imaterial. Este artigo ainda apresentará as ações que vêm sendo desenvolvidas na região carbonífera do Rio Grande do Sul que visam ao desenvolvimento local, tendo como base os seus componentes patrimoniais.

Palavras-chave: Educação. Patrimônio Cultural. Desenvolvimento Local.

Abstract: The main objective of this article is to provide education for Cultural Heritage as a key strategy in the process of knowledge, protection, preservation and promotion of cultural goods. Please note that from this proposal the creation of ideas and actions in favor of local development in a sustainable way is possible. The moment that the subjects recognize the importance of existing equity components in their communities through educational activities that stimulate the senses and affections, it becomes possible to think and forwarding attitudes of social and economic restructuring and recovery of memory and identity through the prism of sustainable development. Insert the theme of Cultural Heritage on the agenda on the management of public spaces of cities is one of the possible ways to combine the issue of Cultural Heritage sustainability. Certainly other possibilities, in terms of local development, are likely to be effected in view of the huge range of possibilities presented by both the material as Intangible Heritage. This article will present the actions that have been developed in the coal region of Rio Grande do Sul aimed at local development based on their equity components.

Keywords: Education. Cultural heritage. Local development. 


\section{Introdução}

Nunca se falou tanto em sustentabilidade como nos últimos anos. Este tema está na pauta de diversos encontros, simpósios, fóruns, etc., onde são discutidas estratégias para garantir a sobrevivência dos empreendimentos humanos e do planeta. Neste sentido, o Patrimônio Cultural surge como um grande aliado nessas ações em favor da sustentabilidade. Como assim? Souza Filho (1997) aponta que o patrimônio ambiental-natural e cultural brasileiro atual é elemento fundamental da civilização e da cultura dos povos, sendo que a possibilidade de seu desaparecimento é assustador, pois ameaça o desaparecimento da própria sociedade. Enquanto o patrimônio natural é a garantia de sobrevivência física da humanidade, que necessita do ecossistema - ar, água e alimentos - para viver, o Patrimônio Cultural é a garantia de sobrevivência social dos povos, porque é produto e testemunho de sua vida.

Mas para que o Patrimônio Cultural realmente se transforme num potente motor do desenvolvimento sustentável das diversas comunidades brasileiras, especialmente tratando-se daquelas consideradas deprimidas socioeconomicamente, é necessário investir em ações educativas que privilegiem 0 conhecimento, proteção, conservação e promoção dos bens culturais. Escolas, universidades, associações de bairro, clube de mães, igrejas, sindicatos, Ongs, Oscips, etc., devem também ser o palco destas ações voltadas ao estímulo das sensibilidades para a preservação do Patrimônio Cultural.

Neste artigo, busca-se discutir: o Patrimônio Cultural visto como recurso potencial para o desenvolvimento local; as formas de atuação educativa para o Patrimônio (estímulo às sensibilidades) como estratégia; e, por fim, a articulação destas ações educativas com a crescente necessidade de avaliarmos, pensarmos e propormos formas de desenvolvimento, alternativas, e por que não, que substituam gradualmente o modelo de desenvolvimento a qualquer custo.
Ao final, toma-se como exemplo as experiências que vêm ocorrendo na região carbonífera do Rio Grande do Sul, área afetada nas mais diversas esferas (social, econômica, ambiental, cultural etc.) pela atividade extrativa do carvão; e que hoje é depositária de um centenário patrimônio industrial à espera por ser ativado adequadamente e assim servir de base para a construção de uma comunidade democrática e sustentável.

\section{Patrimônio Cultural como recurso}

O artigo 216 da Constituição Federal (1988) assim define o Patrimônio: "[...] bens de natureza material e imaterial, tomados individualmente ou em conjunto, portadores de referência à identidade, à ação, à memória dos diferentes grupos formadores da sociedade brasileira". Salienta-se que a Constituição de 1988 ampliou este conceito, ou seja, chegando assim à definição de Patrimônio Cultural. Enquanto, outrora, valorizava-se um discurso patrimonial centrado na defesa da memória nacional sacralizada, com uma forte tendência ao tombamento de conjuntos arquitetônicos ligados ao barroco representativos da herança europeia, branca e cristã; a partir da década de 1970, houve uma guinada, fruto do debate nacional que começava a ganhar corpo em meio a uma conjuntura que assistia a criação da Lei da Anistia, o processo de constituição da Assembleia Nacional Constituinte e as greves que assolavam o Brasil entre as décadas de 1970 e 1980.

O Patrimônio Cultural, dentro desta ampla visão, transformou-se, então, num importante recurso entre as diversas comunidades, capaz de promover o desenvolvimento local em termos econômicos e sociais. Embora esta questão seja muitas das vezes alvo de críticas, como o fato, por exemplo, da reconversão do Patrimônio Cultural para servir de meio de fruição cultural disponível a determinados grupos sociais que possuem capital para usufruí-lo (gentrification), não pode-se negar as potencialidades deste vir a se tornar uma saída para zonas empobrecidas (hotelaria, moradia de aluguel, implantação de empresas, etc.), respeitando, 
logicamente, as leis que regulam a sua proteção e as populações implicadas no processo.

É importante destacar que o Patrimônio Cultural é um recurso não renovável, porém transformável e reprodutível, que vem a ser o "[...] único recurso, juntamente com a população, que se encontra em toda a parte e que basta procurar para encontrá-Io". (VARINE, 2012, p. 19).

Mesmo uma casa modesta, como casas operárias do início do século $X X$ nas regiões mineradoras ou industriais, representa um patrimônio importante para seus proprietários, mas também para a comunidade ao seu redor: um capital para os primeiros, um pedaço de paisagem e um elemento de conjunto residencial para a segunda. Ora, o desenvolvimento local, neste caso um programa de reconversão econômica, pode valorizar ou, ao contrário, reduzir a nada esse capital e destruir um quadro urbano tradicional, sem contrapartida satisfatória. (VARINE, 2012, p. 26).

O Patrimônio Cultural também destaca-se como recurso importante na valorização da memória e da identidade das comunidades, promovendo desta maneira a auto-estima. Em relação a esta colocação convém destacar:

Quem abandona suas origens entra sem norte no porvir. Caminhante sem farol na noite escura, assim é o povo quando levado apenas pelo interesse imediato. De fato, não mais poderá ser chamado autenticamente de povo. Formará um imenso agregado humano, deambulando sem rumo. Despencará para a condição de massa. Seus integrantes serão apenas átomos perdidos $e$ isolados no turbilhão estonteante da civilização contemporânea. (PATRIMÔNIO..., 2014, s.p.).

As potencialidades do Patrimônio Cultural fazem deste um importante recurso, muitas das vezes negligenciado pelos seus detentores. Este olhar para o Patrimônio Cultural como componente essencial da dinâmica da vida social das comunidades em todas as suas nuances, entre elas a história, a memória e a identidade, se vê, na maioria das vezes, obliterado por diversas razões. Do ignorar a participação de diversos grupos sociais na construção da história ao avanço da especulação imobiliária, vários são os motivos que colocam a pauta do Patrimônio Cultural como sendo um campo de disputas e, por vezes, até sem a devida atenção no debate nacional.

Para que este recurso seja reconhecido como elemento importante na busca pelo desenvolvimento local, é necessário articular ações voltadas à educação para o Patrimônio Cultural. Assim é possível, além de conhecer os bens culturais, pensar e encaminhar atitudes de reconversão social e econômica e de valorização da memória e identidade, sob o prisma do desenvolvimento sustentável, especialmente em áreas deprimidas nos campos social e econômico.

\section{A educação para o Patrimônio Cultural como estratégia}

Inserir as comunidades ${ }^{1}$ no debate sobre a importância da proteção dos seus componentes patrimoniais requer investir em ações educativas.

Estes investimentos - que não se reduzem somente ao capital monetário, mas também ao capital humano - devem ocorrer nos diversos ambientes de ensino e aprendizagem. Para a difusão de atividades de valorização do Patrimônio Cultural local, voltadas especificamente às escolas, torna-se importante a existência de políticas públicas que estimulem este tipo de prática, através do apoio e engajamento das Secretarias de Educação, sendo o investimento na formação de professores o alicerce desta construção. É fato que esta prática ainda não é uma realidade. É, portanto, em meio a outros espaços educativos que a temática do Patrimônio Cultural vem recebendo maior atenção e sendo consolidada, como é o caso das

\footnotetext{
1 A antropóloga Eunice Durham considera que a 'ideia de comunidade' é um mito da nossa transformação política. Todo o conceito de comunidade está preso à noção de igualdade, de convivência etc. Pensar na comunidade urbana é muito complicado, se não totalmente falso. E não há nada de que se fale mais no país ultimamente do que em comunidade. É a coisa que menos existe e sobre a qual mais se fala. (FONSECA, 2009, p. 210 apud ARANTES, 1984, p. 55). Neste artigo o conceito de comunidade está relacionado a um agrupamento de pessoas em torno de uma atividade em comum. Como exemplo cita-se a comunidade escolar, constituída basicamente por pais, alunos e profissionais da educação (professores e técnicos).
} 
ações da Oscip Defender ${ }^{2}$, na região carbonífera do Rio Grande do Sul, como veremos mais adiante.

O processo de educação das comunidades para o Patrimônio Cultural, em todos os espaços educativos, deve passar primeiramente pela própria definição do conceito de Patrimônio. Este procedimento é imprescindível na tarefa de reconhecimento dos bens dos quais as populações são depositárias, para que posteriormente possam articularem-se a favor de sua preservação. Para tanto, alguns aspectos específicos do conceito devem ser enfatizados, a fim de que se supere o senso comum e seja evitada a difusão da ideia de "tirania do patrimônio", infelizmente assumida pelos menos precavidos.

Observa-se um olhar reducionista em relação ao Patrimônio Cultural, pairando entre os diversos segmentos da sociedade. O primeiro aspecto diz respeito à questão dos valores. Atrela-se ao Patrimônio, muitas das vezes, apenas 0 valor histórico, quando este também pode vir a abarcar questões de memória e identidade. Quando o sentido está relacionado apenas ao valor histórico, surge uma questão que gera muitas interpretações distorcidas, especialmente entre os leigos no assunto: o que é histórico e o que não é? Sabe-se que por muito tempo a história dita "oficial", ensinada nos bancos escolares, nos apresentava apenas alguns fatos políticos e personalidades como sendo históricos, não atentando-se para o fato, por exemplo, de que as camadas populares, com suas personagens e fatos, também fazem parte do motor que faz girar a história. Lamentavelmente, esta mentalidade aparece sob a forma de discursos reacionários - "isto é história e isto

\footnotetext{
2 A Defender é uma associação da sociedade civil, pessoa jurídica de direito privado, de caráter cultural, sem fins lucrativos, de duração indeterminada, regida por Estatuto e pelas demais disposições legais que Ihe forem aplicadas, com sede e foro em Cachoeira do Sul (RS). Em 27 de junho de 2008, recebeu o título de Utilidade Pública concedido pela Prefeitura de Cachoeira do Sul (RS), através de Decreto Municipal nำ 273. A Defender atua na elaboração e execução direta de projetos, programas ou planos de ações, doação de recursos físicos, humanos e financeiros ou prestação de serviços intermediários de apoio a outras organizações sem fins lucrativos e a órgãos do setor público que atuam nas áreas da cultura, patrimônio cultural, turismo cultural e social, meio ambiente, cidadania, desenvolvimento sustentável, economia criativa e solidária. Disponível em: < http://defender.org.br/quem-somos/>. Acesso em 30 out. 2015.
}

não é" - que petrificam a mentalidade de muitos em detrimento do benefício de poucos e impedem o avanço das políticas de valorização do Patrimônio Cultural e, consequentemente, do desenvolvimento sustentável das comunidades. O valor histórico não pode ser caracterizado como tendo maior legitimidade que, por exemplo, o valor relacionado à memória que representa determinado bem cultural. O Patrimônio não pode ser avaliado por uma "hierarquia de valores".

Outro aspecto importante a ser destacado é o fato de reduzir o Patrimônio Cultural à pedra e cal (FONSECA, 2009). Não é somente de bens edificados que se compõe o Patrimônio Cultural de uma cidade, estado ou país. Observa-se o quanto o conceito de Patrimônio Imaterial alargou os horizontes sobre a temática, lembrando que a materialidade também guarda em si elementos de imaterialidade.

Em 2003, após uma série de esforços, que incluíram estudos técnicos e discussões internacionais com especialistas, juristas e membros dos governos, a UNESCO adotou a Convenção para a Salvaguarda do Patrimônio Cultural Imaterial. Essa convenção regula o tema do patrimônio cultural imaterial e, assim, complementa a Convenção do Patrimônio Mundial, de 1972, que cuida dos bens tangíveis, de modo a contemplar toda a herança cultural da humanidade. A Recomendação de Paris (2003) definiu o Patrimônio Imaterial da seguinte maneira:

Para efeitos da presente Convenção, 1. Entende-se por "património cultural imaterial" as práticas, representações, expressões, conhecimentos e competências - bem como os instrumentos, objectos, artefactos e espaços culturais que lhes estão associados que as comunidades, grupos e, eventualmente, indivíduos reconhecem como fazendo parte do seu património cultural. Este património cultural imaterial, transmitido de geração em geração, é constantemente recriado pelas comunidades e grupos em função do seu meio envolvente, da sua interacção com a natureza e da sua história, e confere-Ihes um sentido de identidade e de continuidade, contribuindo assim para promover o respeito da diversidade cultural e a criatividade humana. Para efeitos da presente Convenção, só será tomado em 
consideração o património cultural imaterial que seja compatível com os instrumentos internacionais relativos aos direitos humanos existentes, bem como com a exigência do respeito mútuo entre comunidades, grupos e indivíduos, e de um desenvolvimento sustentável. (PATRIMÔNIO..., 2016, s.p.).

Serve como exemplo, desta imaterialidade contida na materialidade, a atual insistência pelo o uso do asfalto em vias públicas que possuem pavimentação de pedras ou ladrilhos. Além do dano à materialidade - trazendo consigo consequências ambientais - também detrata o ofício dos lapidadores de pedras (o canteiro) ou mesmo dos artífices de ladrilhos.

Não bastasse estes olhares relacionados aos valores e à natureza dos bens, vivemos uma realidade em que os sujeitos estão anestesiados pelos imediatismos. É difícil encontrar pessoas dispostas a se engajar em projetos a longo prazo. A educação para o Patrimônio Cultural, ao contrário, é assim: um projeto a longo prazo, que necessita de mãos, mentes e cultivo constante.

Como superar estes reducionismos e imediatismos que comprometem o conhecimento, proteção, conservação e promoção dos bens culturais? Por mais que existam medidas de proteção jurídicas extremamente importantes, tendo em vista os inúmeros danos e ameaças que ocorrem, afirmase, cada vez mais, a ideia de que as práticas educativas voltadas para o Patrimônio Cultural devem ser vistas como estratégia essencial para a preservação dos bens culturais e, como será visto adiante, consequentemente, como ferramentas de desenvolvimento local.

Primeiramente, é importante enfatizar que a educação para o patrimônio não deve reduzir-se à doutrinação adquirida através da aplicação de fórmulas prontas e nem a mero entretenimento, pois desta maneira não poderá jamais produzir frutos duradouros, ou seja, cidadãos e cidadãs comprometidos com a preservação dos bens culturais de todas as naturezas. Levando em conta que o patrimônio também está relacionado à questão da afetividade, é importante atentar-se ao estímulo das sensibilidades.
O cuidado com a Sensibilidade se traduz e se descortina na abertura despojada, na disposição de nossas potencialidades humanas, de nossos sensos perceptivos, pela relação coexistencial entre a corporeidade e a espiritualidade e se desdobram em processos compreensivos e vivenciais. Processos que vislumbram a inteireza in-tensiva da condição humana. Dis-posição para a percepção, a compreensão dos fenômenos, da complexidade e da inteireza do existir. (ARAÚJO, 2009, p. 203).

É necessário que o trabalho de "alfabetização patrimonial" (HORTA et. al., 1999) possa associar-se à dimensão das artes em geral como veiculadoras da afetividade. Música, dança, pintura, literatura, teatro etc., devem ser fontes de inspiração que atrelam a dimensão do Patrimônio Cultural ao sentimento de pertencimento. Já dizia Rubem Alves que "[...] Os sentidos brutos são os sentidos em si mesmos. Os sentidos se educam ao serem tocados pela poesia." (ALVES, 2005, p. 46). É necessária, portanto, uma educação para os sentidos, quando se trabalha com a educação para o Patrimônio Cultural. Sem este quesito, corre-se o risco de transformar este processo num emaranhado dogmático de "pode" e "não pode" sem sentido.

Trabalhar a imaginação, sentindo os cheiros, os sons, vislumbrando as cores e suas matizes e descrevê-los em poesia, música, pintura, etc., pode vir a ser o primeiro passo. Relacionar estas impressões geradas pela imaginação com as memórias é um exercício a ser desenvolvido. Através das falas, interconectam-se os fragmentos de memórias e costuram-se novos enredos no presente, pois a memória trata-se também de uma reconstrução continuamente atualizada do passado (CANDAU, 2011). Desvelar as nuanças dos bens culturais nem sempre é uma tarefa fácil e de resultados imediatos. 
Imagem 1: Ruínas da antiga Usina Termoelétrica de Arroio dos Ratos (RS): inúmeras possibilidades de estímulo à sensibilidade patrimonial.

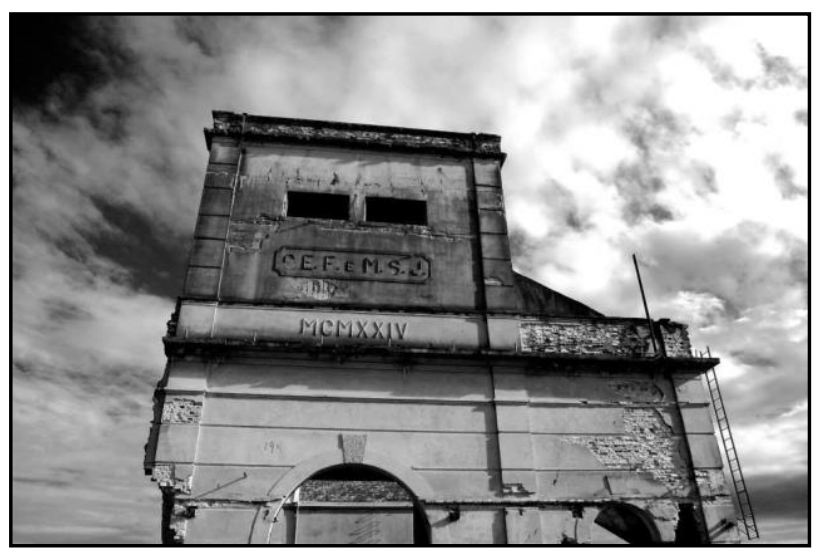

Fonte: STOCKER, Jr., 2013, (s.p.).

É sempre importante frisar que a educação para o Patrimônio Cultural trata-se de um processo a longo prazo que requer paciência e cultivo constante. Mesmo que seja um processo que deve estar disponível a todas as idades, deve atentar-se de que quanto mais cedo ele for estabelecido, ou seja, entre as crianças, mais frutos serão possíveis de serem colhidos. Há virtude na vagareza (ALVES, 2010). Ao invés de correr contra o tempo, o que tem sido a realidade de defesa do Patrimônio Cultural, o cultivo vagaroso e produtivo da promoção da consciência patrimonial pode ser uma saída para o que enfrentamos no presente quanto às questões patrimoniais.

Tratando-se tanto de atividades a serem desenvolvidas, utiliza-se de um exemplo prático de promoção da educação para o Patrimônio Cultural, para ilustrar as ideias acima descritas. Ao convidar um grupo para visitar um sítio arqueológico industrial, por mais simples que a ideia seja, pode se transformar numa proposta bem interessante. trabalho com a realização de um inventário afetivo é uma boa opção para iniciar.

Não desconsiderando a importância do instituto do tombamento, há de se considerar a relevância dos inventários, especialmente quando compartilhados. Estes também apresentam-se como instrumentos importantes no processo de conhecer, proteger, conservar e promover o patrimônio cultural.

Uma boa metodologia de inventário deveria inicialmente entender o espaço estudado seja ele rural, urbano ou metropolitano; entender os significados e a trajetória histórica do lugar e seus elementos simbólicos. Deveria, ainda, prever formas de participação da população, pois é ela que se relaciona com o lugar e tem conhecimento e informações em primeira mão [...]. A partir disso é possível selecionar de forma mais correta e abrangente os bens de interesse cultural. (STOCKER JR, 2015, s.p.).

O processo de inventário compartilhado é importante no reconhecimento dos bens culturais e também pode se transformar em estratégia educativa.

No entanto, é indispensável que os processos de seleção de bens culturais materiais prevejam uma etapa de participação da comunidade - isso se não for possível promover a participação permanente. A comunidade local é única portadora de informações importantes, detentora de saberes, experiências e mesmo dos caminhos para outras fontes. A comunidade que vive no local tem uma trajetória que precisa ser levada em consideração, detentora dos valores mais 'imateriais' de cada bem edificado. Mesmo em centros urbanos globalizados, a comunidade é aquela que convive e se relaciona diariamente com aquele espaço, e é conhecedora, portanto, de suas deficiências e potencialidades. (STOCKER JR, 2013, s.p.).

O exercício das subjetividades simultâneas (VARINE, 2012) é extremamente importante na elaboração dos inventários compartilhados. Assim, se estabelece a reunião e o confronto de opiniões, buscando a maior integração da comunidade ao processo e não restringindo a um pequeno número de pessoas específicas a tomada de decisões e o compartilhamento de responsabilidades. É necessário, portanto, desfazer barreiras sociais, econômicas e culturais, a fim de que o patrimônio possa ser protegido e conservado de forma compartilhada com o Estado, exercendo suas funções, mas também com a comunidade sendo coparticipante do processo. O pilar do desenvolvimento local foi construído; convém, todavia, discutir acerca da finalidade deste processo. 
40 desenvolvimento local sustentável como finalidade

A ideia de sustentabilidade está relacionada à sobrevivência, como perenidade dos empreendimentos humanos e do planeta. Desta maneira:

O conceito de sustentabilidade ambiental refere-se às condições sistêmicas segundo as quais, em nível regional e planetário, as atividades humanas não devem interferir nos ciclos naturais em que se baseiam tudo o que a resiliência do planeta permite e, ao mesmo tempo, não devem empobrecer seu capital natural, que será transmitido às gerações futuras. (MANZINI; VEZZOLI, 2005, p. 75).

Já o conceito de desenvolvimento sustentável, que por sua vez se vê relacionado ao tema da sustentabilidade, vem a ser refletido a partir da seguinte colocação:

A ideia de desenvolvimento, em termos economicistas, é insustentável. O simples dogma básico do pensamento predominante, que diz que uma economia tem que crescer sempre, já é um absurdo. Nada pode crescer sempre, muito menos num espaço limitado, pois não há como aumentar o território, as florestas, os lagos, os rios, os oceanos, a atmosfera. Eis porque o pensamento econômico, que predomina hoje, é suicida. Não podemos continuar olhando o planeta como um almoxarifado gratuito de fundos infinitos. (AZEVEDO, 2014, p. 135).

A Conferência de Estocolmo, em 1972, chegou à conclusão de que a crescente e desmedida produção, que tem seus primórdios na Revolução Industrial (carvão e petróleo - emissão de gás carbônico), é a causa da degradação ambiental. Nesta Conferência, não houve a construção de nada efetivo como solução à situação colocada em pauta, porém a pauta continuou em voga, sendo mais tarde rediscutida novamente.

Em 1987, com a construção do Relatório "Nosso Futuro Comum", há o surgimento do conceito de desenvolvimento sustentável, que é o crescimento caminhando juntamente com o equilíbrio ambiental. Assim foram propostas as três esferas da sustentabilidade: econômica (melhor distribuição de renda), social (melhoria na perspectiva de vida) e ambiental (melhor consciência ambiental).

Como o Patrimônio Cultural relaciona-se à questão do desenvolvimento sustentável? É importante salientar que, durante a Cúpula da Terra, realizada em 1992, no Rio de Janeiro, tendo suas sequências organizadas em 21 agendas locais, reforçaram e deram legitimidade na integração do Patrimônio, primeiramente natural, após cultural, nos planos do desenvolvimento sustentável. (VARINE, 2012). Mais recentemente, houve a realização da Conferência das Nações Unidas sobre Desenvolvimento Sustentável (CNUDS) ${ }^{3}$ - a Rio +20 - , que por sua vez discutiu aspectos envolvendo a proteção do Patrimônio Cultural como parte da caminhada rumo ao desenvolvimento sustentável. Após a realização da Conferência, a cidade do Rio de Janeiro (paisagens cariocas entre a montanha e o mar) ingressou na lista do Patrimônio Mundial da UNESCO como Paisagem Cultural. Este reconhecimento permite não somente a preservação dos aspectos naturais da paisagem como também sociais inerentes a este contexto patrimonial.

Para alcançar o desenvolvimento local sustentável, com base nos componentes patrimoniais, é necessário estimular pessoas-recurso nas próprias comunidades (VARINE, 2012), que possam assim atuar como multiplicadoras desta consciência em defesa do Patrimônio Cultural, como meio de construção de uma consciência e sociedade sustentável.

Como exemplo da busca pela implantação desta ideia, destaca-se o trabalho desenvolvido por associados e delegados da Defender no Rio Grande do Sul. No caso da região carbonífera do Rio Grande do Sul ${ }^{4}$, impactada nas três esferas levantadas pelo

\footnotetext{
3 Conferência das Nações Unidas sobre Desenvolvimento Sustentável, a Rio+20, foi realizada de 13 a 22 de junho de 2012, na cidade do Rio de Janeiro. A Rio+20 foi assim conhecida porque marcou os vinte anos de realização da Conferência das Nações Unidas sobre Meio Ambiente e Desenvolvimento (Rio-92) e contribuiu para definir a agenda do desenvolvimento sustentável para as próximas décadas. Disponível em:

http://www.rio20.gov.br/sobre_a_rio_mais_20.html>. Acesso em 30 out. 2015.

4 No Rio Grande do Sul, a Microrregião Carbonífera do Baixo Jacuí compreende os municípios de Arroio dos Ratos, Barão do Triunfo, Butiá, Charqueadas, Eldorado do Sul, General Câmara,
} 
conceito de sustentabilidade, devido aos anos de extração e queima do carvão mineral, é importante salientar as ações do delegado regional da Oscip e associados locais, que vêm buscando promover uma efetiva forma de educação para o Patrimônio Cultural que tenha como prioridade o desenvolvimento local. As ações iniciais realizadas por este grupo são: a realização de visitas aos municípios que compõem a região, com palestras e oficinas sobre o conceito Patrimônio Cultural e meios de proteção legais, tendo como finalidade a formação de pessoas-recurso nas comunidades; diagnóstico acerca do Patrimônio Cultural na região; atuação direta, buscando a intervenção do Ministério Público em situações de dano ao Patrimônio Cultural local.

IMAGEM 2: Oficina Inventários do Patrimônio Cultural em Butiá-RS. Grupo Coração do Mineiro - Sindicato dos Mineiros de Butiá-RS (2015).

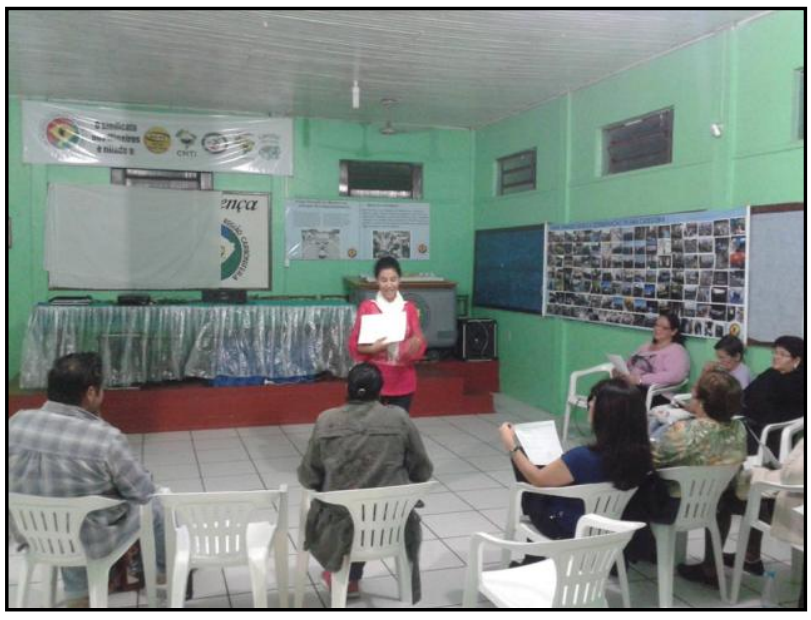

Fonte: Acervo pessoal da autora.

O caso mais recente de dano ao Patrimônio Cultural da região ocorreu na cidade de Butiá, onde a maior parte dos vestígios de um antigo espaço industrial do início século $\mathrm{XX}$, ligado à mineração de carvão (Antigo Poço Borges de Medeiros e suas

Minas do Leão, São Jerônimo e Triunfo. "Esta área está compreendida entre os paralelos $29^{\circ} 37^{\prime}$ e $30^{\circ} 38^{\prime}$ de latitude Sul

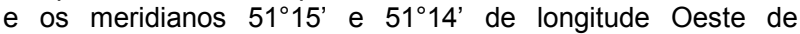
Greenwich”. (HASENACK; GUERRA, 2000, p. 15). Neste território, encontra-se ainda uma subdivisão: a chamada região carbonífera tradicional, formada pelos municípios onde o carvão foi descoberto e que deram origem à exploração do minério em escala industrial. oficinas), foram derrubados, restando apenas algumas ruínas e criando um imenso vazio no centro da cidade. A retirada ilegal de tijolos, sua venda e a possibilidade de especulação imobiliária representada nesta situação são alarmantes e demonstram a necessidade urgente de um projeto sistêmico voltado à educação para o Patrimônio, como essencial para evitar possíveis danos futuros ao que resta de exemplares industriais neste município.

A indústria carbonífera teve papel importante, durante o período da Revolução Industrial (séculos XVIII e XIX). As máquinas a vapor, por exemplo, funcionavam adequadamente, devido à utilização do carvão mineral como combustível. Desta maneira, esta indústria contribuiu para o avanço considerável nas áreas do transporte e do processo de produção. Entretanto, aos poucos, esse panorama foi modificando-se, gradativamente. $\mathrm{Na}$ atualidade, observa-se que o progressivo barateamento de energias alternativas e a pressão social e governamental sobre os investidores, estão provocando uma onda global de desinvestimento em usinas termoelétricas, o que, consequentemente, atinge a indústria do carvão mineral.

O processo de desindustrialização que envolve diversos setores (ferrovias, fábricas têxteis, siderúrgicas, minas, etc.), incute marcas nas comunidades que vivenciaram 0 auge destes processos econômicos. Incluem-se entre estas marcas, as memórias em torno de determinados ofícios, o abandono de espaços que outrora foram de trabalho, fragmentos de sentimentos e práticas comuns e, no caso, nestas comunidades mineiras, também os vestígios ambientais.

José de San Martín, no século XIX, já anunciava em tom profético que um povo que confia sua subsistência em um só produto, suicida-se (GALEANO, 2013). As regiões detentoras de bacias carboníferas, possivelmente já foram assombradas pelo fantasma da redução das atividades extrativas ou mesmo do fim da mineração do carvão ${ }^{5}$.

\footnotetext{
${ }^{5}$ A Região Carbonífera do Baixo Jacuí (Rio Grande do Sul Brasil), por diversos motivos, passou por inúmeros tempos de crise em relação às atividades de mineração do carvão. 0 incentivo às matrizes energéticas limpas (energia eólica, solar,
} 
A exploração dos recursos naturais possui suas limitações, e não são poucas. No caso da exploração do carvão mineral, além da degradação causada ao meio ambiente (embora atualmente as empresas mineradoras advoguem o contrário, alegando para isso o uso de técnicas de extração menos violentas e de recomposição do solo minerado, conforme autorização e fiscalização de órgãos ambientais), é impossível negar também o legado da depressão econômica deixado a diversas regiões do mundo que nesta atividade se empenharam por anos.

Com relação à busca pelo desenvolvimento sustentável, no espaço do patrimônio industrial, é válida a sugestão de Gómez e González (2003, p. 29), em considerar cuidadosamente as necessidades atuais e futuras da comunidade local, a fim de priorizar os possíveis usos alternativos:

\section{$[\ldots]$}

Humedales y lagunas artificiales;

Escuelas de deportes de riesgo, escalada, rocódromos;

Centros de congresos y convenciones;

Parques de atracciones, zoológicos, botânicos;

Anfiteatros y foros para actuaciones y espectáculos;

Usos medioambientales: Aulas de naturaleza;

Zonas de ocio activo: Centros multiaventura;

Usos recreacionales: áreas de paseo;

Vertederos de residuos (R.T.P., R.S.U., etc.);

Zonas urbanizable o residenciales;

Usos agropecuarios o forestales;

Instalaciones y polígonos industriales;

$[\ldots]$

A preservação do Patrimônio Cultural deve cumprir com sua função social. Através de ações educativas é possível, por exemplo: mapear espaços,

biogás, etc.), por exemplo, aparece entre os recentes fatores desfavoráveis à utilização do carvão mineral. Esta situação contribuiu para o fechamento de poços como, por exemplo, o Poço Otávio Reis em Charqueadas (Rio Grande do Sul), que encerrou suas atividades no início da década de 1990. Ainda observamos, entre as diversas cidades que compõem a região, a redução do processo extrativo, o que gerou uma drástica diminuição dos postos de trabalho. especialmente antigos espaços industriais dos quais a região é rica; pensar nas inúmeras possibilidades de novos usos sociais e colocá-las em prática de maneira a contribuir, inclusive, com a melhoria e gestão dos espaços públicos. A reabilitação, especialmente destes friches industriais, pode parecer, num primeiro momento, onerosa e sem grandes perspectivas. Porém, ao invés da derrubada indiscriminada para a construção de novos empreendimentos, é urgente que possamos olhar para estes lugares, anteriormente insustentáveis (antigas minas, termoelétricas), como locais doravante sustentáveis; e esta nova percepção só é possível através de um processo de educação que não se canse de esclarecer o conceito de Patrimônio Cultural e a sua relevância no contexto da sociedade atual.

\section{Considerações finais}

Como parte do alicerce que irá se construir, ações voltadas ao desenvolvimento local de maneira sustentável, está a educação voltada ao Patrimônio Cultural. Os bens culturais (não renováveis, porém transformáveis) são extremamente importantes para compor uma gama de projetos voltados ao desenvolvimento local. Porém, sem um trabalho educacional sistêmico voltado a conhecer, proteger, conservar e promover os bens culturais, partindo do estímulo das sensibilidades, a batalha em torno da defesa do Patrimônio Cultural estará fadada à participação de poucas pessoas e concentrando a maior parte dos seus esforços na situação de danos iminentes.

Logicamente, deve-se levar em conta a conjuntura atual, onde prevalecem os interesses econômicos utilitários, onde as populações são praticamente forçadas a aderirem a determinadas ideias, sem ao menos oferecerem resistência, justamente pelo fato de desconhecerem a temática da preservação do Patrimônio Cultural. Entretanto, é importante destacar que "todo o território determinado sem o respeito por seus componentes patrimoniais não pode servir para um desenvolvimento local 
equilibrado e sustentável". (VARINE, 2012, p. 19). Portanto, a educação para o Patrimônio Cultural, como ferramenta essencial para a construção de uma sociedade democrática e sustentável, é uma pauta fundamental dentro do contexto atual.

\section{Referências}

ALVES, Rubem. Educação dos sentidos e mais. Campinas: Verus, 2005. 2010.

A pedagogia dos caracóis. Campinas:Verus,

ARANTES, Antônio Augusto (Org.). Produzindo o passado. São Paulo: Brasiliense, 1984.

ARAÚJO, Miguel Almir Lima de. Os sentidos da sensibilidade e sua fruição no fenômeno do educar. Educação em Revista. Belo Horizonte. v. 25, n. 02, p. 199-222, ago. 2009.

AZEVEDO, Plauto Faraco. Ecocivilização: ambiente e direito no limiar da vida. 3. ed. Revista dos Tribunais, 2014.

BRASIL. Constituição Federal de 1988. Promulgada em 5 de outubro de 1988. Disponível em <http://www.planalto.gov.br/ccivil_03/constituicao/con stituição.htm>. Acesso em 31 out. 2015.

CANDAU, Joël. Memória e identidade. São Paulo: Contexto, 2011.

FONSECA, Maria Cecília Londres. O patrimônio em processo: trajetória da política federal de preservação no Brasil. 3. ed. Rio de Janeiro: UFRJ, 2009.

GALEANO, Eduardo. As veias abertas da América Latina. Porto Alegre: L\& PM, 2013.

GÓMEZ, D. J. Carvajal; GONZÁLEZ, A. El papel de los parques y museos mineros en el desarrollo sostenible.Re Metallica, [S.I.], p. 26-36, Enero, 2a época. 2003.

HASENACK, Heinrich; T. GUERRA. A área de estudo. In: CENTRO DE ECOLOGIA DA UFRGS.Carvão e meio ambiente. Porto Alegre: Editora da Universidade, 2000.p. 15-17.

HORTA, Maria de Lourdes Parreiras; GRUNBERG, Evelina; MONTEIRO, Adriane Queiroz. Guia básico de educação patrimonial. Brasília, DF: Instituto do Patrimônio Histórico e Artístico Nacional, 1999.

MANZINI, E.; VEZZOLI, C. O desenvolvimento de produtos sustentáveis: os requisitos ambientais dos produtos industriais. São Paulo: Editora da Universidade de São Paulo, 2005.
PATRIMÔNIO cultural: a importância do tombamento do núcleo histórico de Resende Costa. Disponível em: < http://www.jornaldaslajes.com.br/colunas/meioambiente/patrimonio-cultural-a-importancia-dotombamento-do-nucleo-historico-de-resendecosta/705>. Acesso em 31 out. 2015.

PATRIMÔNIO cultural imaterial. Disponível em: $<$ http://www.unesco.org/new/pt/brasilia/ culture/worldheritage/intangible-heritage/>. Acesso em 06 mar. 2016.

SOUZA FILHO, Carlos Frederico Marés de. Bens Culturais e Proteção Jurídica. Porto Alegre: Unidade Editorial, 1997.

STOCKER JR, Jorge Luis. Desmistificando os inventários de patrimônio cultural edificado. Campo Bom, 10 fev. 2015. Disponível em: <http://dzeit. blogspot.com.br/2015/02/desmistificando-osinventarios-de.html>. Acesso em: 24 fev. 2015.

Patrimônio cultural: possibilidades e desafios da participação da sociedade nos inventários. Campo Bom, 4 set. 2013. Disponível em: <http://dzeit.blogspot.com.br/2013/09/ patrimoniocultural-possibilidades-e.html>. Acesso em: $24 \mathrm{fev}$. 2015.

VARINE, Hugues de. As raízes do futuro: o patrimônio a serviço do desenvolvimento local. Porto Alegre: Medianiz, 2012. 